\title{
LIMITES DO SURREALISMO NA POESIA DE Murilo Mendes
}

\author{
Luisa Destri* \\ Universidade de São Paulo, bolsista Capes
}

\begin{abstract}
Resumo
Este texto discute a influência do surrealismo na poesia amorosa de Murilo Mendes (1901-1975), um dos quatro grandes poetas modernistas brasileiros, a partir do modelo de leitura proposto por Roland Barthes em Le plaisir du texte. São considerados principalmente poemas do livro As metamorfoses (1944), com o objetivo de flagrar o movimento entre uma margem sensata e outra subversiva, conforme propõe o ensaísta francês. Observa-se assim como o espelhamento na vanguarda resulta em ambiguidades, pois obedece ao desejo de crítica à realidade, mas serve também à afirmação do sujeito, afastando o risco (politicamente desejado) de sua perda ou dissolução.
\end{abstract}

Palavras-chave: Literatura brasileira, modernismo, leitura de poesia, surrealismo.

Recibido: 10 de enero de 2016

Aprobado: 16 de mayo de 2016

*Dirección electrónica: luisadestri@gmail.com 


\section{LUISA DESTRI}

\section{Limits of surrealism in the poetry of Murilo Mendes}

This essay discusses the influence of Surrealism on the love poetry of Murilo Mendes (1901-1975) - one of the greatest modernist Brazilian poets -, based on the model proposed by Roland Barthes in $L e$ plaisir du texte. Mostly from As metamorfoses (1944), the poems are analyzed according to their duplicity, their movement between an obedient and a subversive edge. The surrealistic heritage, reflected on the poems, turns out to be ambiguous. While it gives shape to a criticism of reality, it also serves as affirmation for the subject, who remains away from the (politically desired) risk of loss or dissolution.

Keywords: Brazilian literature, modernism, poetry analysis, surrealism.

\section{Cómo citar este artículo}

APA: Destri, L. (2016). Limites do surrealismo na poesia de Murilo Mendes. Poligramas, No. 42, junio. Pp.: 95-109

MLA: Destri, Luisa. "Limites do surrealismo na poesia de Murilo Mendes". Poligramas 42 (2016): pp. 95-109 Print.

Chicago: Destri, Luisa. 2016. Limites do surrealismo na poesia de Murilo Mendes. Poligramas 42 (junio): pp. 95-109 
Aspecto mais evidente da especificidade de Murilo Mendes (1901 - 1975) no Modernismo brasileiro, a inspiração surrealista representa um dos principais problemas críticos envolvendo sua obra. Embora jamais tenha integrado formalmente o movimento, e apesar de não haver adotado procedimentos automáticos para a composição de seus textos, o próprio poeta confessou: "Abracei o surrealismo à moda brasileira, tomando dele o que mais me interessava: além de muitos capítulos da cartilha inconformista, a criação de uma atmosfera poética baseada na acoplagem de elementos díspares" (Mendes, 1994, pp. 1237-1238).

Se reconhece amplamente a influência, reiterando e ecoando as palavras do poeta ${ }^{1}$, a crítica raramente atenta ao primeiro elemento enumerado como herança surrealista - os capítulos da cartilha inconformista -, limitando-se a apontar a afinidade estilística ${ }^{2}$. Isto talvez porque, no Brasil, país historicamente receptivo à vida cultural francesa, o próprio surrealismo não tenha tido desdobramentos amplos ${ }^{3}$, o que acabou por lhe determinar também a compreensão crítica.

A dimensão ética da herança surrealista se delineia com clareza na lírica amorosa de Murilo Mendes ${ }^{4}$ : como um aspecto da relação sujeito-objeto, o encontro entre o eu e a amada sintetiza as apirações e expectativas relacionadas à alteridade; já a força do sentimento é capaz de perturbar os limites do cotidiano, lição que a poesia muriliana herda dos escritos de André Breton e dos versos de Paul Éluard. Nesses poemas, ademais, o horizonte afirmativo do autor torna-se claro, com intensidade comparável, quero crer, apenas ao lirismo amoroso dos dois autores

${ }^{1}$ Além do texto citado anteriormente, é o caso também de "A poesia e o nosso tempo", em que menciona "a aproximação de contrários, a aliança dos extremos", que emprega em busca da "imagem mais direta possível, abolindo as passagens intermediárias" (Mendes, 2014, p. 251). Os fragmentos fazem lembrar a seguinte passagem do Manifesto do surrealismo (1924): "La valeur de l'image dépend de la beauté de l'étincelle obtenue ; elle est, par conséquent, fonction de la différence de potentiel entre les deux conducteurs".

${ }^{2}$ A exceção mais notória é o estudo de Valentim Facioli: dedicado ao surrealismo no Brasil, credita ao nacionalismo que marcou as artes brasileiras no Modernismo a impossibilidade de se implantar, aqui, a "radicalidade da aventura surrealista", que demandava a "militância organizada num espaço público". Sua ressonância no país só poderia estimular o "uso privado", isto é, o surrealismo reduzido a procedimentos estilísticos - ou casos como o de Murilo Mendes, cujo "espírito surrealista" se apresentava "em versão conformista e conciliadora" (1994, p. 174).

${ }^{3}$ Sérgio Lima, em torno de quem, a partir dos anos 1960, formou-se em São Paulo um grupo mais organizado, oferece neste link um histórico dessas manifestações: http://www.triplov.com/ surreal/sergio_lima.html.

${ }^{4}$ Trata-se da hipótese que investigo em minha tese de doutorado, cujos primeiros resultados sintetizo neste texto. 


\section{LUISA DESTRI}

franceses. Isto para não mencionar elementos de inegável semelhança, como a crença na mulher como mediadora da salvação terrestre e a preferência, comum a Murilo e Breton, por elementos anfíbios, como o coral, na seleção do material poético.

Para o estudo comparativo, tão importantes quanto as semelhanças são as diferenças - e os poemas de amor são valiosos também para a compreensão dos limites da influência do surrealismo. A partir deles, pretendo, neste texto, discutir como a relação da poesia muriliana com o surrealismo resultou em ambiguidades, pois deu forma à relação negativa com a realidade, mas inspirou também o amor à cultura tradicionalista, na contramão dos pressupostos da vanguarda. Partirei, para isso, da leitura de um poema em particular, que em seguida irei considerar em um conjunto mais amplo de poemas. Entendo o surrealismo a partir da síntese exposta por Ferdinard Alquié em Philosophie du surréalisme e do estudo crítico de Peter Bürger, para quem "os movimentos europeus de vanguarda podem ser definidos como um ataque ao status da arte na sociedade burguesa" (2012, p. 96), conforme formulação de Teoria da vanguarda. Por considerar essa influência uma das formas específicas do inconformismo em Murilo Mendes, procuro refletir sobre seu potencial crítico a partir do modelo interpretativo proposto por Roland Barthes em Le plaisir du texte. Isso implica pensar a cultura como uma margem - da qual a vanguarda, com seu impulso questionador e destrutivo, procura se distanciar. Realizando um movimento ambíguo, a poesia de Murilo Mendes concretiza também uma espécie de erotismo: ora buscando a implosão tipicamente surrealista, ora querendo-se monumento da cultura, movimenta-se, em seus melhores momentos, nessa fenda aberta entre margens ${ }^{5}$.

Um dos poemas que melhor ilustram as afinidades de Murilo Mendes com o surrealismo está no livro As metamorfoses, escrito entre 1938 e 1941 e publicado em 1944:

${ }^{5}$ Traduzo e emprego livremente as expressões utilizadas por Barthes: "duplicité", "bords" "subversion", “faille" (1973, pp. 14-18). 


\section{Estudo para uma Ondina}

Esta manhã o mar acumula ao teu pé rosas de areia,

Balançando as conchas dos teus quadris.

Ele te chama para as longas navegações:

Tua boca, tuas pernas, teu sexo e teus olhos escutaram.

Só teus ouvidos é que não escutaram, ondina.

Minha mão lúcida sacode a floresta do teu maiô.

Ao longe ouço a trompa da caçada às sereias

E um peixe vermelho faz todo o oceano tremer.

Tens quinze anos porque já tens vinte e sete,

Tens um ano apenas...

Agora mesmo nasceste da espuma,

E na incisão do ar líquido alcanças o amor dos elementos.

Eminentemente solar, porque ambientado em uma manhã na orla, o poema é um poderoso exemplar das metamorfoses referidas no título do livro. Dados básicos do conhecimento objetivo - para não dizer científico, como a divisão dos seres vivos em reinos e as propriedades físicas dos elementos - são perturbados. Logo no primeiro verso, reúnem-se o vegetal e o mineral ("rosas de areia"); na última linha, a "incisão" implica a presença de um sólido, fraternalmente unido ou fundido a um líquido que é também gasoso... O centro de convergência desses elementos é o corpo da mulher - conforme o segundo verso, ele mesmo parcialmente transfigurado em um envoltório que, feito de calcário, protege animais aquáticos, pressupondo assim uma cadeia de transformações.

A fluidez é absoluta, e culmina, na estrofe final, em um movimento de vaivém. As quebras entre os versos nono e undécimo, somadas à desordem da sequência numérica (quinze, vinte e sete, um), enlaçam o leitor no balanço do poema. A ondulação é o princípio básico de composição: o próprio mar alonga-se no nome da amada; ela avança e recua, superando o tempo com a naturalidade das ondas. 


\section{LUISA DESTRI}

Nada no poema é gratuito, e tudo se reúne sob o nome dessa mulher. Tornado substantivo genérico pela adoção da inicial minúscula, Ondina espraia-se como a totalidade do cenário. Se por sua força a ligação entre substâncias é, no último verso, identificada ao amor, os "elementos" podem bem representar tudo o que, aparentando incongruência, harmonicamente se reúne no quadro estabelecido pelo poema.

Aqui, como em outros poemas de Murilo Mendes, a amada é uma mulher-sereia, o que em si constitui um dos índices da afinidade com o surrealismo. Ondina, ou Ondine, como a Mélusine de Breton, é uma ninfa das águas, remetendo à mitologia transmitida desde a Odisseia de Homero. Enquanto na epopeia o herói é amarrado ao mastro e os companheiros têm os ouvidos tapados, no poema Ondina é quem se priva da audição. Todo o seu corpo "escuta", porém, e, assim como Ulisses, se debate intensamente sob o chamado das sereias. Curiosamente, neste poema não é a amada que exerce um perigoso poder de atração, pois ela mesma é destinatária do apelo para navegar. Já o amante, como Ulisses, tem ouvidos livres, mas o que escuta está "ao longe", não representando propriamente uma tentação. A mulher, que não ouve o chamado do mar, está protegida da perdição, apesar da resposta de seu corpo.

$\mathrm{O}$ fato de o chamado ser feito pelo mar implica duplo deslocamento - em relação não apenas a Ondina, como também ao eu lírico. Embora o sexto verso indique, na contundente imagem erótica, que o sujeito toca a mulher, a sutileza do segundo verso sugere a capacidade do mar de lhe fazer frente: mergulhado na água, o corpo da amada entrega-se a seu movimento; a água lhe alcança em uma porção eloquente do corpo, conforme sinalizado pela escolha do termo "concha" - que prolonga a cadeia das metamorfoses ao nomear o sexo feminino. Todo o corpo de Ondina excita-se diante do chamado; a atração, tradicionalmente exercida pelas ninfas, toma-a agora como objeto.

Antes de prosseguir na leitura do poema, vale a pena lembrar que, alguns anos após a composição de Murilo, o mito das sereias serviria a uma decisiva reflexão de Adorno e Horkheimer sobre os caminhos da civilização ocidental. Em Dialética do esclarecimento, publicado em 1947, mas escrito quando os autores estavam nos Estados Unidos, protegidos da ameaça nazista, o episódio narrado por Homero é tomado 
como figuração antecipada da relação entre dominação e trabalho na civilização burguesa. Lê-se a estratégia de Ulisses para ouvir o canto das sereias sem a ele sucumbir como alegoria da divisão da consciência humana necessária ao progresso. De um lado, "a promessa irresistível de prazer" que consistiria na dissolução do sujeito, entretanto evitada como preço a pagar pela conquista do suposto aperfeiçoamento; de outro, a suposta autopreservação, o pretenso empenho do homem em conservar-se como indivíduo a fim de sustentar a própria civilização, que contudo the tolhe a individualidade (1985, p. 44).

O poema muriliano representaria o reverso do episódio homérico: a amada, figura mítica operadora de metamorfoses, deve permanecer em terra; as navegações e as caçadas - como empreitadas primeiras da civilização - é que representam a verdadeira ameaça. Nesse mundo representado às avessas, cabe ao eu lírico cuidar para que não aniquilem o canto da sereia. Dessa forma, e a partir da exposição de Adorno e Horkheimer, em "Estudo para uma Ondina" se articulam três forças valorizadas continuamente na poesia de Murilo Mendes, em oposição ao que é preciso sucumbir diante do avanço da civilização ocidental: a própria arte, o encontro amoroso e o feminino.

O programa subjacente ao poema coincide com os pressupostos surrealistas, que, reivindicando potências da linguagem para além da mera comunicação, identificaram a ação social a um problema de expressão, propondo libertar o homem das banalidades e coerções do cotidiano a partir de três pilares: o amor, a poesia e a liberdade. Assim, a partir do trabalho com a linguagem, o artista empenha-se em derrubar os obstáculos que impedem o homem de viver segundo sua inerente plenitude. Desse modo, como afirmação de amor e de liberdade, a poesia surrealista procura denunciar a insuficiência do real e a superficialidade do estilo de vida burguês, almejando, em última instância, reverter a separação, causada pela ciência e pela técnica, entre a consciência humana e o real.

O que amor, poesia e liberdade têm em comum é a capacidade de produzir o encontro do homem com a totalidade - ou seja, o encontro de seus genuínos desejos, tornando evidente o que permanecia oculto. Daí a necessidade de arquitetar uma linguagem livre da objetividade. 
Ao propor a livre-associação como princípio construtivo do discurso, o surrealismo rompe com a lógica que estrutura o pensamento dominante, patente na linguagem corrente. Uma nova linguagem corresponde a uma nova forma de pensamento, sinalizando uma realidade em que os desejos humanos estejam projetados. Assim, a desrealização [“déréalisation" (Alquié, 1977, p. 91)] lograda pela poesia, longe de corresponder a um desejo de fuga para o irreal ou o sonho, é um meio de penetração em uma esfera mais verdadeira que o mundo objetivo. Nesse mundo mais verdadeiro, inexiste a separação entre o objetivo e o subjetivo: o sujeito se identifica com a própria matéria de sua linguagem, e a linguagem passa a ter por referente o que antes era apenas abstrato. Uma vez unidos sujeito e real, a objetividade deixa de ser hostil aos impulsos humanos mais primordiais, refazendo-se como projeção de desejos realizados.

Em "Estudo para uma Ondina", a fluidez da composição e as imagens insólitas apontam para a fusão entre sujeito e objeto - mas a fusão final, entre os amantes, permanece apenas sugerida. O cenário é suspenso após a poderosa imagem que encerra a segunda estrofe ("um peixe vermelho faz todo o oceano tremer"), o que se confirma no estancamento do tempo na estância final, por força do vaivém da amada.

Embora o encontro seja fonte de imagens poéticas - o que talvez constitua o horizonte afirmativo do poema -, a união não chega a se realizar. Essa suspensão pode ser lida como uma das modalidades dos limites que os amantes encontram em outros poemas pertencentes ao livro As metamorfoses que retratam encontros.

"Poema lírico" descreve o voo dos amantes à altura, para longe dos "aparelhos mecânicos" e de "[...] homens bárbaros/ Que fuzilam crianças com bonecas no colo" (Mendes, 1994, p. 322). A afirmação do idílio é tão intensa que o casal ocupa um espaço absoluto, de que ninguém mais participa. Tal pureza só poderia resultar em fragilidade, e o resultado é que o fecho, em vez de concluir a descrição do idílio, acaba por colocá-lo em suspensão, já que se trata de uma pergunta. "Para que organizar tempo e espaço?", questiona o sujeito que havia composto um quadro livre justamente dessas categorias.

Também em "Os amantes submarinos", um dos mais belos poemas 
do autor, a expectativa da separação subjaz à descrição do idílio. Como mostrou Murilo Marcondes de Moura, no poema, que retrata o encontro nas "fundas regiões onde dorme o veleiro", o casal se mantém "à espera" de que "o irreal não se levante em aurora" - sendo por isso identificável à alba, gênero medieval em torno da "situação dos amantes que se encontram à noite e devem-se separar com o nascer do dia" (Moura, 1995, p. 85). Como em "Poema lírico", fica assinalada a fronteira entre fantasia amorosa e realidade.

Essa presença de limiares onde deveria haver superação de limites individuais pode ser lida como um desafio à tarefa que os próprios poemas se propõem. Em primeiro lugar, porque, embora se dediquem a cantar o amor realizado, mantêm o par em suspensão quanto à fusão amorosa. Trata-se, além disso, de poemas em primeira pessoa que apresentam esse eu em uma situação contraditória, pois lhe cabe apresentar o encontro de que participa. Dividido entre a vivência em que está implicado e um modo de apresentação que depende do "defrontar-se objetivo" (Staiger, 1997, p. 77) com os acontecimentos, o eu fica, em última instância, impedido de realizar a dissolução típica do lirismo. O efeito é, portanto, de distanciamento: o limite vivenciado pelo par e representado pelo poema inscreve-se, assim, na própria expressão do sujeito.

Essa perspectiva diante do objeto descrito (no caso desses poemas, o encontro amoroso) pressupõe a existência de um ponto de vista a partir do qual se possa observar - embora sua identificação seja dificultada em situações como a de "Estudo para uma ondina", dada a formação do par. No seguintes trechos, extraídos de diferentes momentos da obra muriliana, o sujeito ocupa curiosos lugares, mesmo quando em presença da amada:

\section{Tentações paralelas}

O Espírito me transporta a um lugar muito alto, me mostra teu corpo decotado.

Poemas (Mendes, 1994, p. 121)

\section{A uma mulher}

Sentado nas nuvens eternas eu te esperarei 
E me nutrirei através dos tempos da nostalgia de ti.

A poesia em pânico (Mendes, 1994, p. 303)

\section{Paternidade}

Espero-te continuamente no limiar do universo

Com todas as formas acesas,

Com a sinfonia dos elementos e o coro solene.

As metamorfoses (Mendes, 1994, p. 121)

\section{Anamorfose}

Assim fiquei à tua espera

Em pé no monumento de areia

- Meu próprio coração absurdo.

As metamorfoses (Mendes, 1994, p. 369)

As implicações de tal configuração para a poesia amorosa podem ser esclarecidas a partir do poema que coloca o amante em um dos mais inusitados locais, "Mulher vista do alto de uma pirâmide", de $O$ visionário (livro escrito entre 1930 e 1933, e publicado em 1941):

Eu vejo em ti as épocas que já viveste

$E$ as épocas que ainda tens para viver.

Minha ternura é feita de todas as ternuras

Que descem sobre nós desde o começo de Adão.

Estás encarcerada nas formas

Que se engrenam em outras desde a corrente dos séculos.

E outras formas estão ansiosas por despontarem em ti.

Quando eu te contemplo

Vejo tatuada no teu corpo

A história de todas as gerações.

Encerras em ti teus ascendentes até o primeiro par,

Encerras teu filho, tua neta e a neta de tua neta.

Mulher, tu és a convergência de dois mundos.

Quando te olho a extensão do tempo se desdobra ante mim. 
Neste poema construído predominantemente por coordenação, as duas ocorrências de subordinação ajudam a compreender o papel que a primeira pessoa assume na obra de Murilo Mendes. Em "Quando eu te contemplo" e "Quando te olho", a subordinação é não apenas gramatical, mas de fato: afinal, para que o corpo feminino seja fonte de revelação, é necessário o olhar do eu lírico. O poema inicia-se, não por acaso, com uma ação do eu ("Eu vejo em ti"), e o título traz "Mulher" como sujeito passivo da oração.

Longe de representarem meras minúcias gramaticais, esses elementos revelam importantes diferenças com relação à formação do par em poemas surrealistas. Nesta composição de Paul Éluard que talvez tenha servido de modelo a Murilo Mendes, a mulher, igualmente sacralizada, é mantida em primeiro plano:

Tu te lèves l'eau se déplie

Tu te couches l'eau s'épanouit

Tu es l'eau détournée de ses abîmes

$\mathrm{Tu}$ es la terre qui prend racine

Et sur laquelle tout s'établit

$\mathrm{Tu}$ fais des bulles de silence dans le désert des bruits

Tu chantes des hymnes nocturnes sur les cordes de l'arc-en-ciel,

Tu es partout tu abolis toutes les routes

Tu sacrifies le temps

À l'éternelle jeunesse de la flamme exacte

Qui voile la nature en la reproduisant

Femme tu mets au monde un corps toujours pareil

Le tien

Tu es la ressemblance ${ }^{6}$.

Enquanto no poema de Éluard a formação do casal é apenas sugerida pelas condições de enunciação - isto é, o elogio sensível a uma segunda

${ }^{6}$ O poema foi incluído em Facile, plaquete lançada em 1935 com Man Ray. 


\section{LUISA DESTRI}

pessoa, no qual a primeira não chega a se revelar -, no de Murilo é o eu quem permanece em primeiro plano. Assim, o poder emancipatório da figura feminina só de dá em função da formação do casal: mais que veículo de salvação terrestre, ela é portadora da chave de um mistério que cabe ao eu lírico desvendar.

Ao dispor dessa maneira o par amoroso, o poema traduz assimetria em espacialidade - e o sujeito, como nos exemplos anteriores, atua como um Todo-Poderoso: com seus poderes criadores, e desde um plano elevado, a tudo contempla e decifra, fazendo as vezes de criador. Mesmo quando não se situa espacialmente nesse ponto superior, caso de "Estudo para uma ondina", cabe-lhe uma tarefa elevada - por exemplo, cuidar para que não aniquilem o canto da sereia. No mesmo livro, o poema "Corrente contínua" atribui ao eu lírico tarefa correlata: "Meus braços acolhem migrações de sereias" (1994, p. 319).

Assim, ainda que, do ponto de vista da imagem, os poemas aqui referidos criem novos e insólitos universos, com relações interiores propondo uma lógica distinta da que rege o mundo objetivo, sua construção obedece a um poder individual, e não à projeção de uma realidade política livre de fronteiras entre a subjetividade e a objetividade. Mesmo num poema como "Manhã", que afirma de modo tão categórico a primazia da poesia (Moura, 1998, p. 129), a superação da insuficiente realidade é obra do poeta. Enquanto o fecho afirma: "É absurdo achar mais realidade na lei que nas estrelas", nos versos iniciais o eu refere-se três vezes a si: "As estátuas sem mim não podem mover os braços/ Minhas antigas namoradas sem mim não podem amar seus maridos/ Muitos versos sem mim não poderão existir" (1994, p. 277 - grifos meus).

Essa maneira de representar o poeta é depositária de uma concepção tradicional da cultura, que aposta nos poderes demiúrgicos da imaginação, confiando que a tarefa superior da arte resida em representar valores humanos supratemporais, livres de qualquer contingência ${ }^{7}-$ traços que, por correlação, o posicionamento elevado do sujeito poéti-

\footnotetext{
${ }^{7}$ Esses são os traços da ideia de Cultura que, segundo Terry Eagleton, vigorou no Ocidente até os anos 1960, quando a noção de cultura como identidade ganhou força, distanciando-se dessa "forma de sujeito universal", que as obras de arte, com uma "capacidade quase divina", supostamente encarnavam. O quadro histórico não implica, vale lembrar, que os surrealistas não tenham questionado a Cultura no início do século XX como depositária de "valores que compartilhávamos simplesmente em virtude da nossa humanidade comum” (2011, p. 61).
} 


\section{Poligramas 42 - junio de 2016}

co parece retomar. Ora, tal concepção foi justamente enfrentada pelas vanguardas, que problematizaram as implicações entre arte e realidade histórica a partir de manifestações artísticas que colocassem em xeque seu estatuto na sociedade burguesa.

A configuração do poeta como Todo-Poderoso, sendo também uma forma de afirmar o poder individual de criação e, portanto, de resistir à dissolução do eu, indica ainda outra forma de limite da afinidade do poeta brasileiro com o surrealismo. Para este, na busca por "recolocar o homem em condições de servir-se da totalidade de suas aptidões" (Bürger como citado em Antunes, 2001,139), a poesia, mais que representar os desejos do sujeito, os realiza na linguagem; segundo, porque deter-se ante a possibilidade de dissolução no outro é o mesmo que resistir ao "desmoronamento do eu cotidiano" (Bürger como citado em Antunes, 2001, 143) - sendo esse desmoronamento a estratégia política do surrealismo.

Situado nas fronteiras do poder individual de criação e da cultura tradicionalista, o poeta faz da linguagem "fonte de grandes prazeres" (Barthes, 2004, p. 15) ${ }^{8}$, em vez de subvertê-la ou destruí-la, como o fazem as vanguardas. Isso não implica dizer que Murilo Mendes tenha se empenhado em um projeto poético conformista, ou que sua poesia tenha procurado formas de amenizar o poder revolucionário do surrealismo. Bem ao contrário, aliás, pois, como confessou, o autor buscou na vanguarda os elementos de sua "cartilha inconformista", e nos poemas relacionados à Segunda Guerra Mundial talvez tenha realizado um aproveitamento do surrealismo mais capaz de dar forma à relação negativa com a realidade (Cf. Moura, 1998).

No que aos poemas amorosos diz respeito, a herança estilística acabou por servir ao amor do poeta pelo poder demiúrgico da cultura universalista, ao contrário do que desejaria politicamente a subversão - talvez porque em uma realidade social e histórica distinta o projeto ideológico do surrealismo não pudesse de fato se implantar (como venho investigando em minha tese) $)^{9}$.

\footnotetext{
${ }^{8}$ No original: "source de grands plaisirs" (Barthes, 1973, p. 19).

${ }^{9} \mathrm{O}$ interesse de tal estudo consiste em compreender a que teria servido, então, a influência surrealista - e não em concluir que diferentes condições históricas fatalmente implicam conformismo.
} 


\section{LUISA DESTRI}

Nesse esquema de leitura, que considera a herança surrealista a partir dos poemas amorosos de Murilo Mendes, contrapõem-se duas margens, que entendo a partir de Barthes: de um lado, a "margem sensata, conforme, plagiária" (2004, p. 11), "que vem da cultura, não rompe com ela" (2004, p. 20); de outro, a "margem subversiva" (2004, p. 12), que "põe em estado de perda", que "faz vacilar as bases históricas, culturais, psicológicas do leitor” (2004, pp. 20-21) ${ }^{10}$. À experiência da fruição eu identificaria a inspiração surrealista como a forma específica da relação negativa que a poesia de Murilo Mendes estabelece com a realidade; à experiência do prazer, a satisfação do sujeito que contempla o universo por ele mesmo criado.

Motivada pelo desejo de expandir os limites da poesia, a relação de Murilo Mendes com o surrealismo tem como limite "l'hédonisme profond de toute culture" (Barthes, 1973, p. 26). O ponto de vista mais abrangente, que venho buscando em minha tese de doutorado, deverá ser capaz de considerar as condições históricas dessa aproximação, permitindo, por um lado, vislumbrar a influência de modo mais completo, inclusive em termos de contexto, e, por outro, flagrar o contínuo movimento de "apparition-disparition" (Barthes, 1973, p. 19) que entre duas margens descreve a poesia de Murilo Mendes. Esse movimento ambíguo, por meio do qual a obra participa da cultura que procurou questionar, é, ao mesmo tempo, a promessa de dissolução e a sua recusa - por parte de um sujeito empenhado em um intenso poder de sedução, e seduzido, por sua vez, pela firme margem da cultura.

\footnotetext{
${ }^{10}$ No original, "un bord sage, conforme, plagiaire" (Barthes, 1973, 14), "qui vient de la culture, ne rompt pas avec elle" (Barthes, 1973, 25); de outro, "le bord subversif” (Barthes, 1973, 15), que "met en état de perte", que "fait vaciller les assises historiques, culturelles, psychologiques, du lecteur" (Barthes, 1973, 25).
} 


\section{Referências bibliográficas}

Antunes, J. P. (2001). Tradução comentada de O surrealismo francês de Peter Bürger. Tese de doutorado em Teoria e História Literária, Universidade Estadual de Campinas, Campinas, SP, Brasil.

Barthes, R. (1973). Le plaisir du texte. Paris: Les Éditions du Seuil.

Barthes, R. (2004). O prazer do texto. (J. Guinsburg Trad.). São Paulo: Perspectiva.

Bürger, P. (2012). Teoria da Vanguarda. (J. P. Antunes Trad.). São Paulo: Cosac Naify.

FACIOLI, V. (1994): "O Brasil e o surrealismo (aspectos do campo da produção artística erudita no período de 1920 a 1950)", Organon, vol. 8, n. 22, pp. 23-38.

Eagleton, T. (2011). A ideia de cultura. (S. C. Branco Trad.) (2 ed). São Paulo: Editora Unesp.

Mendes, M. (1994). Poesia completa e prosa. Rio de Janeiro: Nova Aguilar.

Mendes, M. (2014). Antologia poética. São Paulo: Cosac Naify.

Moura,M. M. (1995). Murilo Mendes: a poesia como totalidade. São Paulo: Edusp.

Moura,M. M. (1998). Três poetas brasileiros e a Segunda Guerra Mundial (Carlos Drummond de Andrade, Cecília Meireles e Murilo Mendes). Tese de doutorado em Teoria Literária e Literatura Comparada, Universidade de São Paulo, São Paulo, SP, Brasil.

StAiger, E. (1997). Conceitos fundamentais da poética ( $3^{\mathrm{a}}$ ed). (C. A. Galeão Trad.). Rio de Janeiro: Tempo Brasileiro. 